\title{
Expectation and cooperation in prisoner's dilemmas: The moderating role of game riskiness
}

\author{
Gary Ting Tat $\mathrm{Ng}^{1} \cdot$ Wing Tung $\mathrm{Au}^{1}$
}

Published online: 1 August 2015

(C) Psychonomic Society, Inc. 2015

\begin{abstract}
This paper investigated the effect of risk orientation, game riskiness, and expectation of cooperation on cooperation in one-shot prisoner's dilemmas (PD). Participants in pairs played $P D$ games that varied on game riskiness such that for half of the games cooperation was more risky than defection (more risky games) while for another half cooperation was less risky (less risky games). They estimated how likely it was that the other player was going to cooperate (expectation of cooperation) before they made their cooperation/ defection decision on each game. Supporting the Goal/ Expectation Hypothesis, we replicated the effect that expectation of cooperation enhanced cooperation. We also found that risk-seeking individuals cooperated more in more risky games whereas risk-averse individuals cooperated more in less risky games. More importantly, we found that game riskiness moderated the effect of expectation of cooperation on cooperation. The positive effect of expectation of cooperation on cooperation was stronger for more risky games than for less risky games. Our results illustrated how the relation between expectation and cooperation as stipulated by the Goal/Expectation Hypothesis was moderated by riskiness of the situations.
\end{abstract}

Keywords Prisoner's dilemma $\cdot$ Risk aversion $\cdot$ Risk orientation $\cdot$ Expectation of cooperation $\cdot$ Game riskiness

A prisoner's dilemma (PD) models a situation that a decision of achieving an optimal individual outcome leads to a suboptimal collective outcome. In a typical two-person PD game,

Wing Tung Au

wintonau@cuhk.edu.hk

1 Department of Psychology, The Chinese University of Hong Kong, Shatin, Hong Kong SAR, China each player decides simultaneously whether to cooperate or defect. If both players choose to cooperate, both receive the reward outcome (R). If one chooses to cooperate and one chooses to defect, the one who defected receives the temptation outcome $(\mathrm{T})$, while the one who cooperated receives the sucker outcome (S). If both players choose to defect, both receive the punishment outcome $(\mathrm{P})$. The dilemma arises when these four outcomes satisfy a condition such that $T>$ $\mathrm{R}>\mathrm{P}>\mathrm{S}$ (Rapoport, 1967). Players unavoidably face risk due to uncertainty of outcomes because choosing cooperation faces the uncertainty of getting either R or S; while choosing defection faces the uncertainty of getting T or P. Understanding how risk is related to cooperation in PD is thus essential. Numerous studies have investigated the relation between an individual's risk orientation and cooperation, but the results were inconsistent (e.g., de Heus, Hoogervorst, \& Dijk, 2010; Glöckner \& Hilbig, 2012; Sabater-Grande \& Georgantzis, 2002). In this paper, we explore further how riskiness of situation and individual difference in risk orientation can influence cooperation by incorporating expectation of cooperation in the context of one-shot PD games in which a game is played once only.

\section{Risk orientation}

Risk orientation is an individual difference characteristic that some people are risk-seeking while some are risk-averse. For example, if individuals are being given two choices: a gamble of getting $\$ 10$ or nothing with an equal chance, or a sure gain of $\$ 5$, some may choose the gamble while some may choose the sure gain.

Research findings regarding risk orientation and cooperation in PD are mixed. Some researchers reported no significant association between risk orientation and 
cooperation (e.g., de Heus et al., 2010; Dolbear \& Lave, 1966). However, Sabater-Grande and Georgantzis (2002) and Parks (2004) found that risk-seeking people cooperated more. Glöckner and Hilbig (2012) found that the effect of risk orientation on cooperation depended on environments, such that risk aversion enhanced cooperation in cooperation-friendly environments only, but not in cooperation-unfriendly environments. $\mathrm{Au}$ et al. (2012) suggested that the inconsistency is due to the ambiguity in defining risk of cooperation and defection in PD. They developed an index of game riskiness $(r)$ such that a PD can be constructed to be more risky or less risky to cooperate.

\section{Game riskiness}

There is no consensus on whether cooperation or defection is a more risky choice. Cooperation could be considered as more risky because it involves a large risk of being exploited by partners and in turn receiving the worst outcome (Parks, 2004; Yamagishi, 1986); cooperation could also be considered as less risky because it preserves one's reputation (e.g., Lam \& Leung, 2007). Whether cooperation is more or less risky could also depend on whether the outcomes are framed as gains or losses (Raub \& Snijders, 1997).

Au et al. (2012) proposed that in a PD the relative risk of the cooperation choice to that of the defection choice can be calculated as $r=(\mathrm{R}-\mathrm{S}) /[(\mathrm{R}-\mathrm{S})+(\mathrm{T}-\mathrm{P})]$, such that the index of game riskiness $(r)$ ranges from 0 to 1 . In essence, $r$ is an index of the variance of the cooperation choice outcomes, $\mathrm{R}$ and $\mathrm{S}$, relative to the variance of the defection choice outcomes, T and P. A game in which the variance of cooperation outcomes is greater than the variance of defection outcomes will have an $r$ value greater than 0.5 that the cooperation choice is said to be more risky than the defection choice. A game in which the variance of cooperation outcomes is smaller than the variance of defection outcomes will have an $r$ value smaller than 0.5 that the cooperation choice is said to be less risky than the defection choice. For simplicity, a PD with $r>0.5$ is denoted as a more risky game while a PD with $r$ $<0.5$ is denoted as a less risky game. The cooperation choice of a PD can be constructed as more risky or less risky while maintaining the game's tendency to induce cooperation as measured by Rapoport's (1967) index of cooperation (K), which ranges from 0 to 1 , such that a game with a larger value of $\mathrm{K}$ should elicit more cooperation than a game with a smaller value of $\mathrm{K}$. Consider Game A [T=247, $\mathrm{R}=239, \mathrm{P}=213, \mathrm{~S}=$ $161]$ and Game B [269, 217, 191, 183]. Both Game A and Game B have the same K value of $(\mathrm{R}-\mathrm{P}) /(\mathrm{T}-\mathrm{S})=(239-213)$ $/(247-161)=(217-191) /(269-183)=0.3$ that players are expected to cooperate at similar rates. However, Game A is a more risky game $(r=(239-161) /[(239-161)+(247-213)]=$
$0.7)$ whereas Game B is a less risky game $(r=0.3)$. Confirming their theoretical predictions, $\mathrm{Au}$ et al. found that risk-seeking individuals cooperated more in more risky games whereas risk-averse individuals cooperated more in less risky games. In this study we would try to replicate this finding that game riskiness moderates the effect of risk orientation on cooperation (Hypothesis 1).

\section{Expectation of cooperation}

Expectation of cooperation concerns how likely we think that the other person is going to cooperate. Without any information, one may apply the principle of indifference to assume that the other person has an equal chance to cooperate or defect (Keynes, 1921). However, individual differences and environmental cues could change our expectation one way or another. For instance, a person with a pro-social social value orientation or higher trust towards others may expect that the other person is more likely to cooperate (Bogaert, Boone, \& Declerck, 2008). A person may also expect the other player to be more likely to cooperate in games with a larger $\mathrm{K}$ value which is more conducive to cooperation (Rapoport, 1967).

Expectation of cooperation enhances cooperation (Kuhlman \& Wimberley, 1976; Liberman, Samuels, \& Ross, 2004). The Goal/Expectation Hypothesis states that a person is likely going to cooperate when one endorses the goal of achieving the reward outcome (R) and one expects that the other person will also cooperate (Pruitt \& Kimmel, 1977). Zettler, Hilbig, and Heydasch (2013) explicitly manipulated the player's expectation by informing players of the probability that their opponents would cooperate. They found that people cooperated more as their expectation of cooperation increased. In the present study, we also expect that the higher the expectation of cooperation, the more likely one will cooperate in PD games (Hypothesis 2).

Expectation of cooperation, however, is not a sufficient condition for cooperation. Batson and Ahmad (2001) found that the effect of expectation of cooperation on cooperation depended on empathy and self-interest of individuals. In the present study, we will examine how the effect of expectation on cooperation could be moderated by game riskiness.

\section{Expectation and its relation to game riskiness}

Assume a player expects that another player will cooperate with a probability of $p$. The expected value of choosing cooperation is $p \mathrm{R}+(1-p) \mathrm{S}$ and the expected value of choosing defection is $p \mathrm{~T}+(1-p) \mathrm{P}$ (Camerer, 1997). When $p$ increases, expected values for both cooperation and defection increase. However, because in a PD the expected value of defection is always greater than that of cooperation for all values of $p$, the 
rational decision is to defect. Nevertheless, studies found that people cooperate to a non-negligible extent even in a one-shot PD (Cooper, DeJong, Forsythe, \& Ross, 1996). The actual expected utility of cooperation may be greater than that of defection due to a feeling of a warm glow after cooperation (Andreoni, 1990), a feeling of guilt after defection (Ketelaar \& $\mathrm{Au}, 2003)$ as well as other psychological factors that make cooperation possible. Despite the fact that the expected value of defection is higher than that of cooperation, we reason that the smaller the difference between expected values of defection and cooperation, the greater the likelihood that one will cooperate. In Appendix A we demonstrate mathematically, for both more risky games and less risky games, how the difference between expected values of defection and cooperation changes as expectation of cooperation changes. Among more risky games, as expectation of cooperation increases, the difference between expected values of defection and cooperation decreases, i.e., defection relative to cooperation is becoming less attractive. Consider Game A with $r=0.7$ as an example. The expected value difference decreases from 43.2 to 16.8 when expectation of cooperation increases from 0.2 to 0.8 . Hence, people should be more inclined to cooperate in more risky games as expectation of cooperation increases. On the contrary, as expectation of cooperation increases among less risky games, the expected values difference increases, i.e., defection relative to cooperation is becoming more attractive. As in Game B with $r=0.3$, the expected value difference increases from 16.8 to 43.2 when expectation of cooperation increases from 0.2 to 0.8 . Hence, people should be less likely to cooperate in less risky games as expectation of cooperation increases. Although an increase in expectation of cooperation enhances cooperation in general, we postulate that this positive effect of expectation of cooperation on cooperation will be moderated by game riskiness. Specifically, we hypothesize that the positive effect of expectation of cooperation on cooperation will be stronger for more risky games than for less risky games (Hypothesis 3).

\section{Method}

\section{Participants}

A total of 146 university students were recruited through a mass mailing system to take part in an individual and group decision-making experiment. The age of participants ranged from 18 to 25 years old ( $M=20$ years). They were promised a show-up fee of HKD\$50 (US\$7) and also a chance to win a variable bonus depending on their decisions. The bonus ranged from HKD $\$ 19$ to $\$ 34$ (US\$2 to 4) in actuality. The experiments were conducted in 14 sessions with four to seven pairs of participants in each session.

\section{Risk gambles}

Risk orientation was measured by eight risk gambles (Holt \& Laury, 2002; Sabater-Grande \& Georgantzis, 2002; Weber, 1988). Each gamble consists of a more risky choice and a less risky choice. Risk orientation is indicated by the proportion of risky choices chosen. Four gambles had two alternatives of a more risky and a less risky option, e.g., an option A with an equal chance winning 475 or 25 tokens, or an option B with an equal chance of winning 275 or 225 tokens. Another four gambles had two alternatives of a risky option and a certainty outcome, e.g., an option A with an equal chance winning 400 or 100 tokens or an option B of a sure-gain of 250 tokens. The eight gambles are presented in Table 1. Two filler gambles with options of randomly generated values were included to mask the purpose of the games. These ten gambles were presented in a randomized order on a paper-and-pencil questionnaire.

\section{Prisoner's dilemma games}

Participants played 28 one-shot PD games. Twelve games were constructed as more risky games with $r=0.65$ or 0.70 at $\mathrm{K}=0.30$ or 0.40 . Another 12 games were constructed as less risky games with $r=0.30$ or 0.35 matching the values of K of the more risky games. A list of the $24 \mathrm{PDs}$ is presented in Table 2. Another four filler games with payoff values generated by random numbers were included to mask the nature of the experiment and they were not analyzed. The payoff values of the games were presented as bar charts. In half of the games, the cooperation and defection options were labeled as A and B respectively, and vice versa for the other half of the games. The 28 games were presented in a randomized order

Table 1 List of eight risk gambles

\begin{tabular}{lll}
\hline Game & Choice A & Choice B \\
\hline 1 & $50 \%$ to get 475 tokens; & $50 \%$ to get 275 tokens; \\
& $50 \%$ to get 25 tokens & $50 \%$ to get 225 tokens \\
2 & $50 \%$ to get 450 tokens; & $50 \%$ to get 300 tokens; \\
& $50 \%$ to get 50 tokens & $50 \%$ to get 200 tokens \\
3 & $50 \%$ to get 425 tokens; & $50 \%$ to get 325 tokens; \\
& $50 \%$ to get 75 tokens & $50 \%$ to get 175 tokens \\
4 & $50 \%$ to get 400 tokens; & $50 \%$ to get 350 tokens; \\
& $50 \%$ to get 100 tokens & $50 \%$ to get 150 tokens \\
5 & $50 \%$ to get 450 tokens; & Certainly get 250 tokens \\
6 & $50 \%$ to get 50 tokens & \\
& $50 \%$ to get 400 tokens; & Certainly get 250 tokens \\
7 & $50 \%$ to get 100 tokens & Certainly get 250 tokens \\
8 & $50 \%$ to get 350 tokens; & \\
& $50 \%$ to get 150 tokens & Certainly get 250 tokens \\
& $50 \%$ to get 300 tokens; & \\
\hline
\end{tabular}

Note In the above table, Option A is always more risky than Option B 
Table 2 The 24 prisoner's dilemma games and their expectation and cooperation rate $(\mathrm{N}=145)$

\begin{tabular}{|c|c|c|c|c|c|c|c|c|c|c|}
\hline Game & $\mathrm{T}$ & $\mathrm{R}$ & $\mathrm{P}$ & $\mathrm{S}$ & $r$ & $\mathrm{~K}$ & EC Mean & EC SD & Coop & $\rho$ \\
\hline 1 & 269 & 217 & 191 & 183 & 0.3 & 0.3 & .39 & .28 & .27 & .50 \\
\hline 2 & 247 & 239 & 213 & 161 & 0.7 & 0.3 & .40 & .30 & .26 & .48 \\
\hline 3 & 279 & 221 & 181 & 179 & 0.3 & 0.4 & .36 & .28 & .22 & .36 \\
\hline 4 & 251 & 249 & 209 & 151 & 0.7 & 0.4 & .41 & .33 & .29 & .64 \\
\hline 5 & 266 & 220 & 194 & 180 & 0.35 & 0.3 & .39 & .29 & .28 & .52 \\
\hline 6 & 249 & 237 & 211 & 163 & 0.65 & 0.3 & .42 & .31 & .26 & .50 \\
\hline 7 & 275 & 225 & 185 & 175 & 0.35 & 0.4 & .40 & .31 & .23 & .57 \\
\hline 8 & 255 & 245 & 205 & 155 & 0.65 & 0.4 & .45 & .32 & .32 & .57 \\
\hline 9 & 292 & 222 & 188 & 178 & 0.3 & 0.3 & .39 & .29 & .23 & .45 \\
\hline 10 & 262 & 252 & 218 & 148 & 0.7 & 0.3 & .43 & .32 & .26 & .62 \\
\hline 11 & 305 & 228 & 175 & 172 & 0.3 & 0.4 & .46 & .33 & .39 & .37 \\
\hline 12 & 268 & 265 & 212 & 135 & 0.7 & 0.4 & .47 & .34 & .30 & .59 \\
\hline 13 & 288 & 226 & 192 & 174 & 0.35 & 0.3 & .38 & .29 & .26 & .46 \\
\hline 14 & 266 & 248 & 214 & 152 & 0.65 & 0.3 & .41 & .30 & .26 & .58 \\
\hline 15 & 300 & 233 & 180 & 167 & 0.35 & 0.4 & .39 & .28 & .23 & .50 \\
\hline 16 & 273 & 260 & 207 & 140 & 0.65 & 0.4 & .43 & .32 & .33 & .55 \\
\hline 17 & 315 & 228 & 185 & 172 & 0.3 & 0.3 & .38 & .29 & .21 & .52 \\
\hline 18 & 278 & 265 & 222 & 135 & 0.7 & 0.3 & .39 & .32 & .18 & .52 \\
\hline 19 & 332 & 235 & 168 & 165 & 0.3 & 0.4 & .41 & .32 & .26 & .50 \\
\hline 20 & 285 & 282 & 215 & 118 & 0.7 & 0.4 & .44 & .35 & .28 & .67 \\
\hline 21 & 310 & 233 & 190 & 167 & 0.35 & 0.3 & .41 & .30 & .23 & .48 \\
\hline 22 & 283 & 260 & 217 & 140 & 0.65 & 0.3 & .41 & .32 & .22 & .48 \\
\hline 23 & 326 & 241 & 174 & 159 & 0.35 & 0.4 & .39 & .29 & .23 & .42 \\
\hline 24 & 291 & 276 & 209 & 124 & 0.65 & 0.4 & .43 & .34 & 28 & .62 \\
\hline
\end{tabular}

Note Payoff values were rounded off to the nearest integers

$T, R, P$, S temptation outcome, reward outcome, punishment outcome and sucker outcome, respectively, $r$ index of game riskiness, $K$ index of cooperation, EC Mean mean of expectation of cooperation for each game, $E C S D$ standard deviation of expectation of cooperation for each game, Coop cooperation rate for each game, $\rho$ Spearman correlation between expectation of cooperation and cooperation for each game

on a paper-and-pencil questionnaire. Figure 1 presents a sample game.

\section{Expectation of cooperation}

Before making decisions on each of the 28 games, participants were asked to what extent they expected the other player would choose A or B by making a mark on a 10-cm horizontal line. A mark on the leftmost position indicates that they thought another person would definitely choose A while the rightmost position indicates that they thought another person would definitely choose B.

\section{Procedure}

Participants were told that they would play two sets of decision-making games. They were told that they had a 20
$\%$ chance determined by a lucky draw that they would receive a monetary bonus depending on their decisions on these games at a rate of HK\$1 for every 200 tokens earned. They were then presented the first set of ten individual decision games, i.e., risk gambles.

The second set of games was two-person decision games, i.e., PD. Participants were briefed in great detail on how to comprehend the payoff matrix and completed a quiz in order to make sure they knew how to play the games and how to indicate expectation of the other person's choices. Participants then drew cards to determine randomly and anonymously whom they would be paired with in playing these games. Participants did not know who their partner was and they were asked not to communicate their decisions with anyone. In order to ensure the one-shot nature of PD games, they received no feedback on their partner's decisions.

After all participants completed all questionnaires, they took a lucky draw, received their show-up fee and bonus, and were debriefed and thanked.

\section{Results}

Data for one participant were excluded due to incompletion of questionnaires so that a total of 145 cases were included in the analysis. Risk orientation was measured by the proportion of more risky options chosen among the eight risk gambles $(M=$ $34 \%, S D=.24)$. The average expectation of cooperation and cooperation rate for all the 24 games were $41 \%$ and $26 \%$, respectively. Table 2 shows the mean and standard deviation of expectation of cooperation, the cooperation rate, and the Spearman correlation between expectation of cooperation and cooperation for each game.

We analyzed the data using generalized estimating equations (GEEs) with an exchangeable structure (Zeger \& Liang, 1986). Because the cooperation/defection decision was a dichotomous variable, an ordinal logistic model was adopted with game riskiness as a dichotomous within-subject factor, expectation of cooperation as a continuous within-subject variable, and risk orientation as a continuous between-subject variable. In the first block, we included in the model the main effects of game riskiness, risk orientation, and expectation of cooperation only. We found a significant main effect of expectation of cooperation on cooperation, $B=3.82, S E=0.38, \chi^{2}$ $(1)=99.97, p<.05$. Supporting Hypothesis 2 , the higher the expectation of cooperation of participants, the greater the likelihood that they cooperated. The main effects of risk orientation and game riskiness were not significant. In the second block, we included three two-way interaction effects in the model. We found a significant Risk Orientation $\times$ Game Riskiness interaction, $B=-.58, S E=0.28, \chi^{2}(1)=4.38, p<.05$. Consistent with previous findings and supporting Hypothesis 1 , risk-seeking individuals cooperated more in more risky 


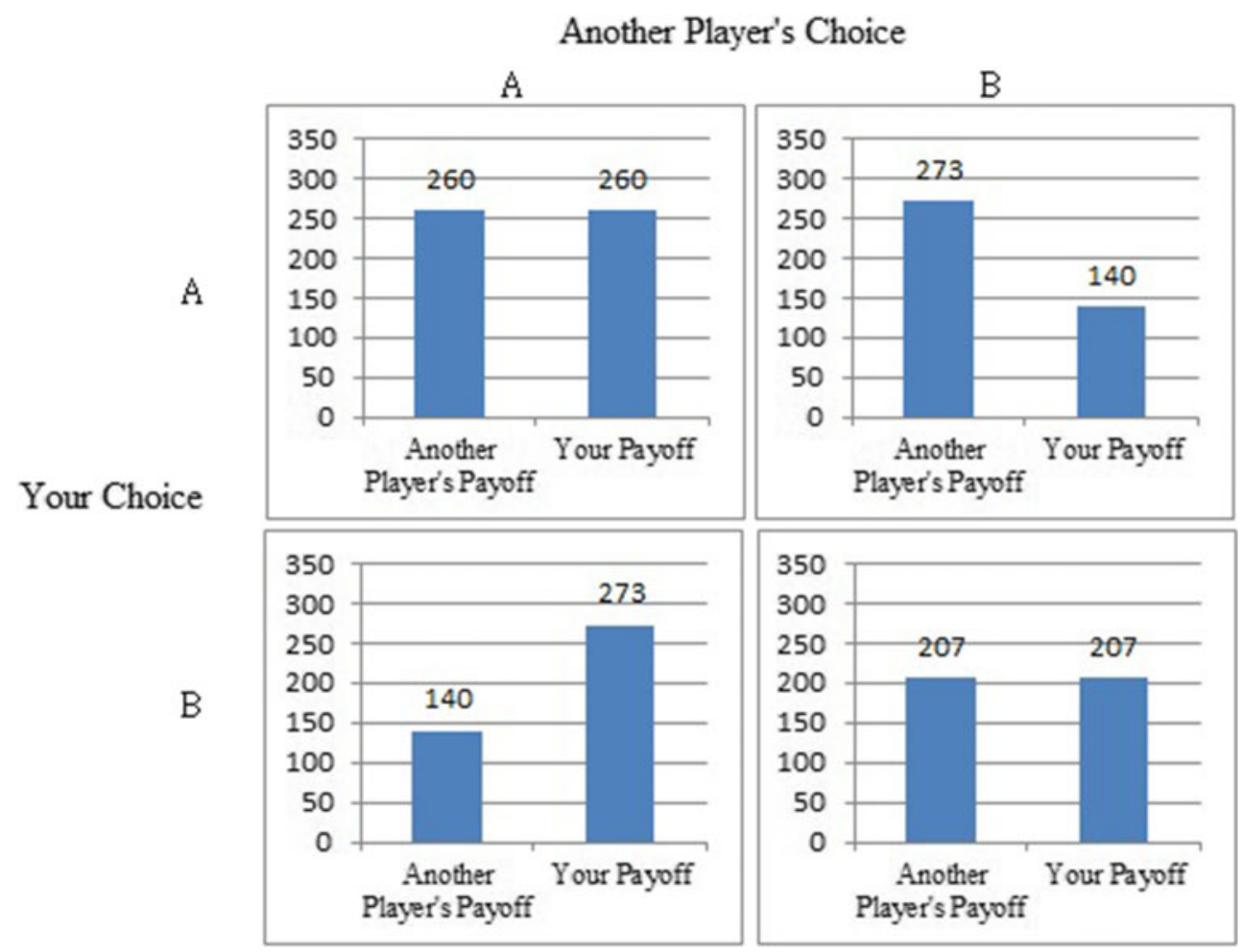

Fig. 1 An example of prisoner's dilemma game

games whereas risk-averse individuals cooperated more in less risky games (Fig. 2). Furthermore, the Game Riskiness $\times$ Expectation of Cooperation interaction was significant, $B=$ $-.69, S E=0.22, \chi^{2}(1)=9.80, p<.05$ (Fig. 3). In order to examine the pattern of interaction, we further computed the

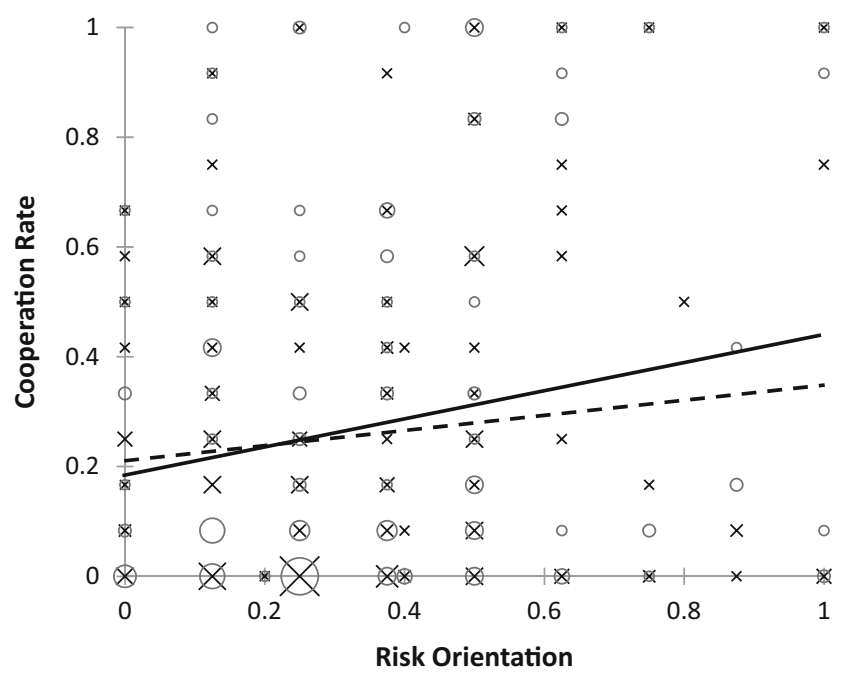

$$
\begin{gathered}
\text { × Less Risky Games — More Risky Games } \\
\text {--- Less Risky Games — More Risky Games }
\end{gathered}
$$

Fig. 2 Regression lines and scatter plot of cooperation rates of less risky and more risky games against risk orientation. Note Size of crosses and dots represents the number of participants falling on that particular point. Each participant has two data points in this plot because each made decisions on both less risky and more risky games
Fisher transformed correlations between expectation of cooperation and cooperation for each game and conducted a paired t-test to compare the difference in correlations between less risky and more risky games, because our PD games were constructed in a way that Game 1 and Game 2, Game 3 and

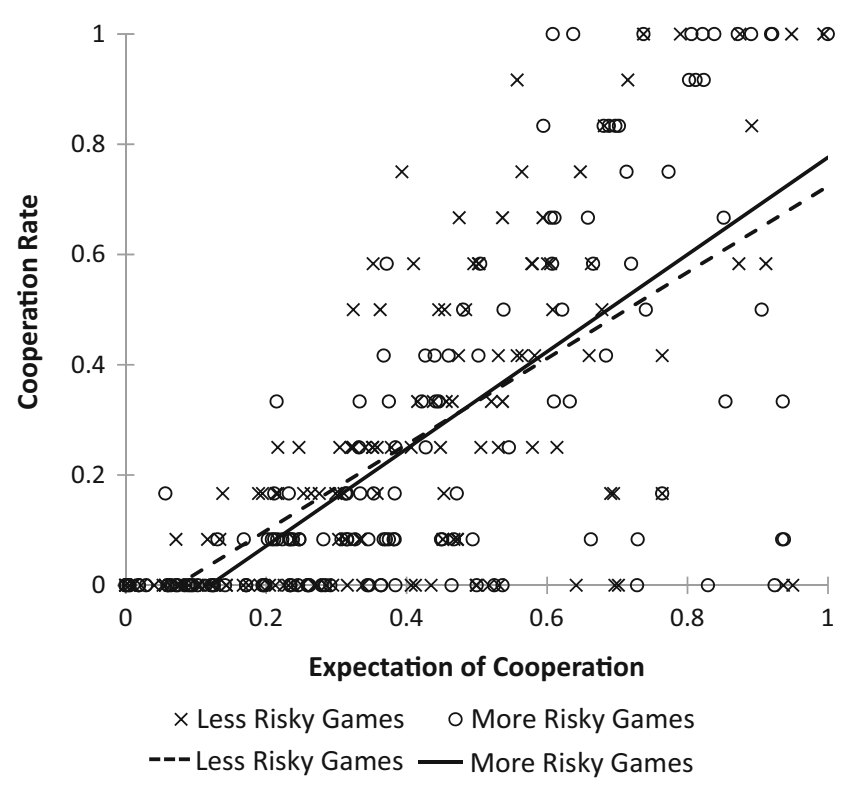

Fig. 3 Regression lines and scatter plot of cooperation rates of less risky and more risky games against expectation of cooperation. Note Each participant has two data points in this plot because each made decisions on both less risky and more risky games 
Game 4, etc. were counterparts of each other such that they had the same value of $\mathrm{K}$ but complementary values of $r$ (i.e., 0.30 vs. $0.70 ; 0.35$ vs. 0.65). Supporting Hypothesis 3 that the positive effect of expectation of cooperation on cooperation was stronger for more risky games than for less risky games, we did find that the average correlation was stronger for more risky games $(z=0.65)$ than for less risky games $(z=0.51)$, $t(11)=-3.16, p<.05$. The Risk Orientation $\times$ Expectation of Cooperation interaction was not significant. Finally, we included the Game Riskiness $\times$ Risk Orientation $\times$ Expectation of Cooperation interaction effect in the model. Nonetheless, the three-way interaction was not significant. Table 3 presents the summary of the GEE results.

\section{Discussion}

In this study, we examined how the effect of expectation of cooperation on cooperation was moderated by game riskiness. Our empirical findings support our mathematical analyses that there is a limiting condition to the Goal/Expectation Hypothesis: Expectation had a stronger effect on cooperation in more risky games; expectation had a weaker effect on cooperation in less risky games. We were also able to replicate previous findings that game riskiness moderated the effect of risk orientation on cooperation.

Our findings support the analysis based on expected values. Firstly, as expectation of cooperation $(p)$ increases, the expected value of cooperation also increases regardless of game riskiness, i.e., the absolute attractiveness of cooperation increases as $p$ increases. Secondly, expectation of cooperation affects the difference between expected values of defection and cooperation, i.e., the relative attractiveness of defection beyond cooperation. In more risky games, cooperation is enhanced by both factors that increases in expectation of cooperation make cooperation more rewarding and at the same time make defection less attractive as compared to cooperation. However, in less risky games, although expectation of cooperation enhances cooperation because it makes cooperation more attractive, expectation of cooperation at the same time undermines cooperation because it makes defection increasingly attractive relative to cooperation.

Put another way, when a person expects the partner is going to cooperate (i.e., high expectation of cooperation), the person may think he or she is likely to get either the T or R outcome. Consider as examples Game A and Game B, which have the same value of index of cooperation $(\mathrm{K})$ but different values of game riskiness $(r)$. The difference in values between the $\mathrm{T}$ and $\mathrm{R}$ outcomes is greater for the less risky Game $\mathrm{B}(\mathrm{T}-\mathrm{R}=52)$ than for the more risky Game $\mathrm{A}(\mathrm{T}-\mathrm{R}=8)$. The relatively larger temptation outcome (vs. the reward outcome) in a less risky game thus induces people to defect. When expectation of cooperation is low, however, a person may think he or she is likely to get either the $\mathrm{P}$ or $\mathrm{S}$ outcome. The difference between $\mathrm{P}$ and $\mathrm{S}$ is greater for the more risky Game A than the less risky Game $\mathrm{B}(\mathrm{P}-\mathrm{S}=52$ vs. 8$)$. The relatively smaller sucker outcome (vs. the punishment outcome) in a more risky game thus induces people to defect.

There are several limitations in our study. In our games we constrained index of cooperation $(\mathrm{K})$ to be either 0.3 or 0.4 . Using games of different values of $\mathrm{K}$ may yield different results. For instance, Glöckner and Hilbig (2012) found that risk-averse people cooperated more in cooperation-friendly environments but not in cooperation-unfriendly environments. Our games with small $\mathrm{K}$ values could be considered to be cooperation-unfriendly environments. Further studies could systematically examine how game cooperativeness may interact with risk orientation and game riskiness to affect cooperation.

Risk orientation may be domain specific. Risk orientation could be divided into five domains, namely financial decisions, health or safety, recreational, ethical, and social

Table 3 Summary of results of generalized estimating equations

\begin{tabular}{|c|c|c|c|c|c|c|c|c|c|}
\hline \multirow[b]{2}{*}{ Variable } & \multicolumn{3}{|c|}{ Model 1} & \multicolumn{3}{|c|}{ Model 2} & \multicolumn{3}{|c|}{ Model 3} \\
\hline & $\mathrm{B}$ & $\mathrm{SE}$ & $\chi^{2}(1)$ & $\mathrm{B}$ & SE & $\chi^{2}(1)$ & $\mathrm{B}$ & SE & $\chi^{2}(1)$ \\
\hline Game riskiness & 0.06 & 0.08 & 0.52 & 0.65 & 0.17 & $14.37 *$ & 0.81 & 0.26 & $9.36^{*}$ \\
\hline Risk orientation & 0.22 & 0.58 & 0.14 & 1.34 & 0.98 & 1.86 & 1.56 & 0.99 & 2.47 \\
\hline Expectation of cooperation & 3.82 & 0.38 & $99.97 *$ & 4.59 & 0.70 & $42.88 *$ & 4.74 & 0.74 & $41.18^{*}$ \\
\hline $\mathrm{GR} \times \mathrm{RO}$ & & & & -0.58 & 0.28 & $4.38^{*}$ & -0.99 & 0.51 & 3.75 \\
\hline $\mathrm{GR} \times \mathrm{EC}$ & & & & -0.69 & 0.22 & $9.80^{*}$ & -0.97 & 0.47 & $4.24 *$ \\
\hline $\mathrm{RO} \times \mathrm{EC}$ & & & & -1.23 & 1.66 & 0.55 & -1.63 & 1.70 & 0.92 \\
\hline $\mathrm{GR} \times \mathrm{RO} \times \mathrm{EC}$ & & & & & & & 0.74 & 0.92 & 0.65 \\
\hline
\end{tabular}

$G R$ game riskiness such that less risky games were coded as "1" and more risky games were coded as " 2 " in this analysis, $R O$ risk orientation that a larger value indicates more risk-seeking, $E C$ expectation of cooperation that a larger value indicates higher expectation of cooperation

$* p<.05$ 
decisions (Weber, Blais, \& Betz, 2002). Our experiment was presented in a financial context. Further studies are needed to investigate how risk orientation domains may influence cooperation in different mixed-motive situations.

Risk orientation can also affect the utility of outcomes of a PD. When utility is taken into account, the prediction could be different from the analysis based on expected values (see Appendix B for the analysis based on expected utility). Although our empirical results were not in line with the analysis based on expected utility, further studies should consider using a risk orientation measure that can estimate the utility curve of each individual and investigate whether individuals behave according to the expected utility analysis.

In this study, participants were asked to indicate their expectation of cooperation towards the other player first and then make their cooperation decision. Asking about their expectation towards the other player may direct them to think from the other player's perspective, which increases their perspective taking and leads to more cooperation (Galinsky et al., 2008). We assume that it may simply elevate cooperation uniformly across both more risky and less risky games and among both riskseeking and risk-averse individuals. Moreover, it is also possible that a player's cooperation behavior induces him or her to think that the other person will also cooperate due to a false consensus effect and a justification of one's own behavior (Ross, Greene, \& House, 1977) so that the causal relation between expectation and cooperation could be interpreted in an opposite way. Nevertheless, these possibilities should not undermine the moderating role of game riskiness between the relation of expectation and cooperation. Further studies could explicitly manipulate expectation of cooperation in order to establish the causal direction directly.

With all these considerations in mind, this paper still provides a clearer picture on how risk in the situations interacts with risk orientation as an individual differences characteristic and expectation of cooperation to affect cooperation behaviors.

Acknowledgments The work described in this paper was fully supported by a grant from the Research Grants Council of HKSAR, China (No. CUHK440109).

\section{Appendix A}

A Mathematical Analysis Illustrating the Relation among Game Riskiness, Expectation of Cooperation and Cooperation Based On Expected Value

Let $x$ be the difference between the expected value of defection and the expected value of cooperation. Let $p$ be the expectation of cooperation and $\mathrm{T}, \mathrm{R}, \mathrm{P}$ and $\mathrm{S}$ be the four outcomes in a prisoner's dilemma game.

$=$ Expected value of defection - Expected value of cooperation

$x=[p \mathrm{~T}+(1-p) \mathrm{P}]-[p \mathrm{R}+(1-p) \mathrm{S}]$

$=p[(\mathrm{~T}-\mathrm{P})-(\mathrm{R}-\mathrm{S})]+\mathrm{P}-\mathrm{S}$

By differentiation with respect to $p$,

$x^{\prime}=(\mathrm{T}-\mathrm{P})-(\mathrm{R}-\mathrm{S})$

Note that index of game riskiness $(r)$ is given by $r=(\mathrm{R}-\mathrm{S}) /$ $[(\mathrm{R}-\mathrm{S})+(\mathrm{T}-\mathrm{P})]$.

Because $r>0.5$ in more risky games such that $\mathrm{T}-\mathrm{P}<\mathrm{R}-\mathrm{S}$, we deduce that $x^{\prime}<0$, which indicates that as $p$ increases, the expected value difference decreases, i.e., the defection choice is becoming less attractive relatively compared to the cooperation choice. Therefore, among more risky games, as expectation of cooperation increases, people should become more cooperative.

Because $r<0.5$ in less risky games such that $\mathrm{T}-\mathrm{P}>\mathrm{R}-\mathrm{S}$, we deduce that $x^{\prime}>0$, which indicates that as $p$ increases, the expected value difference increases, i.e., the defection choice is becoming more attractive relatively compared to the cooperation choice. Therefore, among less risky games, as expectation of cooperation increases, people should become less cooperative.

\section{Appendix B}

An Illustration of the Relation among Risk Orientation, Game Riskiness, Expectation of Cooperation and Cooperation Based On Expected Utility

Let $\mathrm{U}(x)$ be the difference between the expected utility of defection and the expected utility of cooperation and $p$ be the expectation of cooperation.

$$
\begin{aligned}
& =\text { Expected utility of defection }- \text { Expected utility of cooperation } \\
\mathrm{U}(x) & =[p \mathrm{U}(\mathrm{T})+(1-p) \mathrm{U}(\mathrm{P})]-[p \mathrm{U}(\mathrm{R})+(1-p) \mathrm{U}(\mathrm{S})] \\
& =p \quad\{[\mathrm{U}(\mathrm{T})-\mathrm{U}(\mathrm{P})]-[\mathrm{U}(\mathrm{R})-\mathrm{U}(\mathrm{S})]\}+\mathrm{U}(\mathrm{P})-\mathrm{U}(\mathrm{S})
\end{aligned}
$$

By differentiation with respect to $p$,

$\mathrm{U}^{\prime}(x)=[\mathrm{U}(\mathrm{T})-\mathrm{U}(\mathrm{P})]-[\mathrm{U}(\mathrm{R})-\mathrm{U}(\mathrm{S})]$

For a risk-averse individual that follow a concave utility function, when facing a more risky game $(r>0.5)$ such that $\mathrm{T}-\mathrm{P}<\mathrm{R}-\mathrm{S}, \mathrm{U}(\mathrm{T})-\mathrm{U}(\mathrm{P})<\mathrm{U}(\mathrm{R})-\mathrm{U}(\mathrm{S})$, given that $\mathrm{T}>\mathrm{R}>\mathrm{P}>\mathrm{S}$.

Therefore, $\mathrm{U}^{\prime}(x)<0$, which indicates that as $p$ increases, the expected utility difference decreases.

However, for a risk-seeking individual that follow a convex utility function, when facing a more risky game, whether U(T) 
- $U(P)$ is greater or less than $U(R)-U(S)$ cannot be determined because it depends on how risk-seeking an individual is.

In contrast, when a risk-seeking individual faces a less risky game $(r<0.5)$ such that $\mathrm{T}-\mathrm{P}>\mathrm{R}-\mathrm{S}, \mathrm{U}(\mathrm{T})-\mathrm{U}(\mathrm{P})>$ $\mathrm{U}(\mathrm{R})-\mathrm{U}(\mathrm{S})$, given that $\mathrm{T}>\mathrm{R}>\mathrm{P}>\mathrm{S}$. Therefore, $\mathrm{U}^{\prime}(x)>0$, which indicates that as $p$ increases, the expected utility difference increases.

However, when a risk-averse individual faces a less risky game, whether $\mathrm{U}(\mathrm{T})-\mathrm{U}(\mathrm{P})$ is greater or less than $\mathrm{U}(\mathrm{R})-\mathrm{U}(\mathrm{S})$ cannot be determined because it depends on how risk-averse an individual is.

From the above analysis, we can conclude that for riskaverse individuals in more risky games, when expectation of cooperation increases, the difference between the expected utility of defection and cooperation decreases; for riskseeking individuals in less risky games, when expectation of cooperation increases, the difference between the expected utility of defection and cooperation increases. No conclusion about how expectation of cooperation would affect the expected utility difference can be drawn for risk-seeking individuals in more risky games and for risk-averse individuals in less risky games. In this way, a Game Riskiness $\times$ Risk Orientation $\times$ Expectation of Cooperation three-way interaction effect on cooperation could be expected.

\section{References}

Andreoni, J. (1990). Impure altruism and donations to public goods: A theory of warm-glow giving. The Economic Journal, 100(401), 464-477.

Au, W. T., Lu, S., Leung, H., Yam, P., \& Fung, J. M. Y. (2012). Risk and prisoner's dilemma: A reinterpretation of Coombs' re-parameterization. Journal of Behavioral Decision Making, 25(5), 476-490.

Batson, C. D., \& Ahmad, N. (2001). Empathy-induced altruism in a prisoner's dilemma II: What if the target of empathy has defected? European Journal of Social Psychology, 31(1), 25-36.

Bogaert, S., Boone, C., \& Declerck, C. (2008). Social value orientation and cooperation in social dilemmas: A review and conceptual model. British Journal of Social Psychology, 47(3), 453-480.

Camerer, C. F. (1997). Progress in behavioral game theory. The Journal of Economic Perspectives, 11(4), 167-188.

Cooper, R., DeJong, D. V., Forsythe, R., \& Ross, T. W. (1996). Cooperation without Reputation: Experimental Evidence from Prisoner's Dilemma Games. Games and Economic Behavior, 12(2), 187-218.

de Heus, P., Hoogervorst, N., \& Dijk, E. V. (2010). Framing prisoners and chickens: Valence effects in the prisoner's dilemma and the chicken game. Journal of Experimental Social Psychology, 46(5), 736-742.

Dolbear Jr, F. T., \& Lave, L. B. (1966). Risk orientation as a predictor in the Prisoner's Dilemma. Journal of Conflict Resolution, 10(4), 506515 .
Galinsky, A. D., Maddux, W. W., Gilin, D., \& White, J. B. (2008). Why it pays to get inside the head of your opponent the differential effects of perspective taking and empathy in negotiations. Psychological Science, 19(4), 378-384.

Glöckner, A., \& Hilbig, B. E. (2012). Risk is relative: Risk aversion yields cooperation rather than defection in cooperation-friendly environments. Psychonomic Bulletin \& Review, 19(3), 546-553.

Holt, C. A., \& Laury, S. K. (2002). Risk aversion and incentive effects. American Economic Review, 92(5), 1644-1655.

Ketelaar, T., \& Au, W. T. (2003). The effects of feelings of guilt on the behaviour of uncooperative individuals in repeated social bargaining games: An affect-as-information interpretation of the role of emotion in social interaction. Cognition \& Emotion, 17(3), 429-453.

Keynes, J. M. (1921). A treatise on probabilities. New York: Macmillan.

Kuhlman, D. M., \& Wimberley, D. L. (1976). Expectations of choice behavior held by cooperators, competitors, and individualists across four classes of experimental games. Journal of Personality and Social Psychology, 34(1), 69-81.

Lam, K. M., \& Leung, H. F. (2007). Incorporating risk attitude and reputation into infinitely repeated games and an analysis on the iterated prisoner's dilemma. In A. Ghose, G. Governatori, \& R. Sadananda (Eds.), Proceedings of the 19th IEEE International Conference on Tools with Artificial Intelligence (ICTAI'07) (pp. 60-67). Los Alamitos: IEEE Computer Society Press.

Liberman, V., Samuels, S. M., \& Ross, L. (2004). The name of the game: Predictive power of reputations versus situational labels in determining prisoner's dilemma game moves. Personality and Social Psychology Bulletin, 30(9), 1175-1185.

Parks, C. D. (2004). Risk preference as a predictor of cooperation in a social dilemma. In R. Suleiman, D. V. Budescu, I. Fischer, \& D. M. Messick (Eds.), Contemporary Psychological Research on Social Dilemmas (pp. 58-70). Cambridge: Cambridge University Press.

Pruitt, D. G., \& Kimmel, M. J. (1977). Twenty years of experimental gaming: Critique, synthesis, and suggestions for the future. Annual Review of Psychology, 28(1), 363-392.

Rapoport, A. (1967). A note on the index of cooperation for prisoner's dilemma. Journal of Conflict Resolution, 11(1), 100-103.

Raub, W., \& Snijders, C. (1997). Gains, losses, and cooperation in social dilemmas and collective action: The effects of risk preferences. Journal of Mathematical Sociology, 22(3), 263-302.

Ross, L., Greene, D., \& House, P. (1977). The "false consensus effect": An egocentric bias in social perception and attribution processes. Journal of Experimental Social Psychology, 13(3), 279-301.

Sabater-Grande, G., \& Georgantzis, N. (2002). Accounting for risk aversion in repeated prisoners' dilemma games: An experimental test. Journal of Economic Behavior \& Organization, 48(1), 37-50.

Weber, E. U. (1988). A descriptive measure of risk. Acta Psychologica, 69(2), 185-203.

Weber, E. U., Blais, A. R., \& Betz, N. E. (2002). A domain-specific riskattitude scale: Measuring risk perceptions and risk behaviors. Journal of Behavioral Decision Making, 15(4), 263-290.

Yamagishi, T. (1986). The provision of a sanctioning system as a public good. Journal of Personality and Social Psychology, 51(1), 110-116.

Zeger, S. L., \& Liang, K. Y. (1986). Longitudinal data analysis for discrete and continuous outcomes. Biometrics, 42(1), 121-130.

Zettler, I., Hilbig, B. E., \& Heydasch, T. (2013). Two sides of one coin: Honesty-Humility and situational factors mutually shape social dilemma decision making. Journal of Research in Personality, 47(4), 286-295. 